\title{
MEDIAÇÃO E RESOLUÇÃO DE CONFLITOS ESCOLARES: CRIMINALIZAÇÃO OU EDUCAÇÃO?
}

\author{
MEDIATION AND RESOLUTION OF SCHOOL CONFLICTS: \\ CRIMINALIZATION OR EDUCATION?
}

\section{MEDICIÓN Y RESOLUCIÓN DE CONFLICTOS ESCOLARES: ¿CRIMINALIZACIÓN O EDUCACIÓN?}

\author{
Carlos Alberto Máximo Pimenta ${ }^{\mathrm{I}}$ \\ Ligia Maria de Mendonça Chaves Incrocci ${ }^{\mathrm{II}}$
}

REsumo Este artigo faz a reflexão sobre os processos de mediação e resolução de conflitos no interior da escola, em que coloca em pauta a tensão entre criminalização e a educação do aluno envolvido em agressões ou manifestações de violência. Objetiva-se evidenciar os elementos presentes no cotidiano escolar, dentro das possibilidades de suas ações pedagógicas, os quais podem contribuir para a superação de sua postura de criminalização-policial-repressiva. A mediação, técnica no campo das inovações jurídicas aplicada à sociedade para intervenções públicas e privadas de resolução de conflitos, ultrapassa a sua dimensão funcional, dogmática e normativa no campo do direito. Na educação, constitui-se em instrumento de revisão do papel formador da escola. Para esta se faz necessário interpretar os clamores da juventude e as distintas formas de expressão de violência, levando-se em consideração o imaginário, a cultura e os modos de ser, sentir, pensar, viver e experienciar a vida daqueles que compõem o cotidiano escolar.

Palavras-chave: Mediação; Resolução de Conflitos; EducaÇão; ViolênCia na Escola.

I Doutor em Ciências Sociais pela Pontifícia Universidade Católica de São Paulo (PUC/SP); Professor no Programa de Pós-Graduação em Desenvolvimento, Tecnologias e Sociedade (PPG DTecS) da Universidade Federal de Itajubá (UNIFEI) e coordenador do Núcleo de Estudos Interdisciplinares em Desenvolvimento (NEID); e-mail: carlospimenta@unifei.edu.br;

II Doutoranda em Ciências da Tecnologia pela Universidade Federal de São Carlos (UFSCar); mestre em Desenvolvimento, Tecnologias e Sociedade (PPG DTecS / UNIFEI); e-mail: ligia.incrocci@gmail.com. 
Abstract This article is about processes of mediation and conflict resolution inside the school and it puts on the agenda the tension between the criminalization or education of the student involved in aggressions or manifestations of violence. The objective is to highlight the pedagogical actions practiced in the daily school life which may contribute to overcoming their criminalization-police-repressive. Mediation, technique in the field of legal innovations applied to society for public and private conflict resolution, goes beyond its functional, dogmatic and normative dimension in the field of Law. In education, mediation is an instrument for reviewing the formative role of the school. For the school, it is necessary to interpret the cries of youth and the different forms of expression of violence, considering the imaginary, culture and ways of being, feeling, thinking, living and experiencing the lives of those who make up school daily.

Key-words: Mediation; Conflict Resolution; Education; Violence in School.

Resumen Este artículo es una reflexión sobre los procesos de mediación y resolución de conflictos dentro de la escuela, lo que trae consigo la tensión entre la penalización y la educación del estudiante involucrado en ataques o brotes de violencia. Tiene como objetivo poner en evidencia los elementos en la vida cotidiana de la escuela, dentro de las posibilidades de sus acciones pedagógicas, que pueden contribuir a la superación de las prácticas de penalización, de policía y de represión. La mediación es una técnica en el campo de las innovaciones legales aplicadas a la sociedad para la resolución de las intervenciones públicas y privadas para la resolución de conflictos. En la escuela, excede su dimensión funcional, dogmática y normativa en el ámbito de la ley. En la educación, constituye un instrumento de revisión del papel formativo de la escuela, lo que se necesita interpretar los gritos de los jóvenes y las diferentes formas de expresión de la violencia, teniendo en cuenta el imaginario, la cultura y formas de ser, sentir, pensar, vivir y experimentar la vida de los que conforman la rutina escolar.

Palabras clave: la Mediación; Resolución de Conflictos; La Educación; La Violencia en la Escuela.

\section{INTRODUÇÃo}

A proposta não tem a pretensão de caracterizar-se como um modelo ou um formulário-roteiro para as resoluções dos conflitos no interior da escola, embora possa ter repercussão interventiva nas dinâmicas escolares. Apresenta-se em forma de reflexão sobre os processos de mediação e se coloca na pauta das ações educacionais a tensão entre criminalização ou formação do aluno envolvido em manifestações de violência.

O tema "mediação na educação" não é novo, mas se faz pertinente. Da associação entre escola e realidade social é que se vê justificada às questões relativas aos diversos processos de intervenção da violência, uma vez que as atuais sociedades assumem um caráter imperativo na formação das pessoas, obrigatoriamente para crianças, adolescentes e jovens, pelo menos em nível dos discursos científicos e políticos. 
O novo é a aposta em procedimentos de "automediação" de conflitos pela unidade escolar. O crédito da condução desse processo é atribuído aos professores, alunos, supervisores, diretores, merendeiras, pessoal da limpeza, inspetores, a partir das diferentes formas de suas atuações. Estes têm as condições para enfrentar a realidade apresentada, para além da transmissão do conhecimento formal, da organização da vida escolar e da preocupação com a aprendizagem.

A mediação, técnica no campo das inovações jurídicas aplicada à sociedade para intervenções públicas e privadas de resolução de conflitos. Na prática, propõe-se ultrapassar a dimensão funcional, dogmática e normativa do direito e, na educação, se constitui em instrumento de revisão do papel formador da escola. Esta, impõe interpretar os clamores da juventude e as distintas formas de expressão de violência, levando-se em consideração o imaginário, a cultura e os modos de ser, sentir, pensar, viver e experienciar a vida daqueles que compõem o cotidiano escolar.

A “automediação" traz consigo a ideia de responsabilizações que ultrapassem as ações da educação formal, promovendo na prática escolar revisões de seus valores de socialização, pedagógicos e de formação. Dentro desse quadro, pergunta-se: de qual perspectiva a unidade escolar pode contribuir para a resolução de seus conflitos sem a intervenção da polícia e sem o caráter repressivo?

A pergunta abre um leque de questionamentos sobre a ação pedagógica e o papel da educação formal. Restrito ao universo da ação pedagógica, o "ato de educar" não contempla o conjunto de conhecimentos adquiridos pelo aluno fora da escola. Por sua vez, dentro do papel da educação formal, a automediação possibilita o reaprender coletivo, em que professores, alunos, pais, entorno, comunidade, instituição e saberes podem almejar ir além do modelo de educação competitivo.

Objetiva-se evidenciar os elementos presentes no cotidiano escolar, dentro das possibilidades de suas ações pedagógicas, os quais podem superar a postura de criminalização-policial-repressiva e ressignificar as manifestações de conflitos daquele contexto.

Do ponto de vista metodológico, o material coletado tem origem na pesquisa de campo realizada na execução do projeto “Escola e Violências: Processos de 'auto' mediação e resolução dos conflitos no interior da escola". ${ }^{1}$

O local das pesquisas foi o município de Poços de Caldas, interior do Estado de Minas Gerais, mas a reflexão pode ir além desse universo para servir de referência em outras realidades, no sentido de contribuir para futuras práticas educacionais de intervenções dos conflitos ou de manifestações de violência no interior da unidade escolar.

A investigação aconteceu no período de fevereiro de 2014 a fevereiro de 2016, entre inserções na escola, observações do cotidiano de unidades escolares e salas de aula, reuniões formais, conversas informais, solicitações de dados junto da Secretaria de Ensino do município, da Superintendência do Estado e da Polícia Militar.

Financiamento pelo Edital FAPEMIG 13/2012 - Pesquisa em Educação Básica - Acordo CAPES-FAPEMIG, Processo $n^{\circ}$. APQ 03424-12. 
A incursão de campo teve a finalidade de dar voz e vida para todas as pessoas presentes no cotidiano escolar, em que se valorizam as experiências dos envolvidos e se buscou ênfase aos elementos que estão presentes nas relações desencadeadas no cotidiano escolar, as quais ganhavam significados para se constituírem em técnica de mediação. Portanto, realizou-se levantamento dos indicativos de violência no interior da escola para, a partir deles, localizar as ações de encaminhamento que a unidade propõe, uma vez que o processo de automediação tem potencial para reescrever o sentido da escola contemporânea.

Para a triangulação entre pergunta-problema, dados de campo e perspectiva teórica de partida, utilizou a proposta de Bourdieu (1997) descrita no capítulo "Compreender", do livro A Miséria do Mundo, no sentido de levantar as dimensões simbólicas presentes nas relações conflituosas estudadas, visto que a escola se constitui num campo de forças e de disputas sociais, culturais, econômicas, normativas e que compõem um conjunto de práticas, o que o autor chama de habitus. Estes se manifestam por meio de imposições de arbitrários culturais categorizados ou não em "violência simbólica".

Pela noção de "campo" e de "dissimetria social” de Bourdieu (1997, p. 695), privilegiaram-se na observação os discursos hegemônicos, as rupturas, as resistências, a possibilidade de novos sentidos atribuídos nas relações entre os sujeitos. Dentro dessa perspectiva, quatro casos acontecidos no interior da escola estudada foram registrados pelos pesquisadores e apresentados como partida laboratorial de possíveis processos de mediação.

Para organizar a proposta, dividiu-se o texto em três partes distintas, mas interligadas e correlacionadas. A primeira, traz os conceitos que organizam e orientam a concepção de mediação de conflitos. A segunda, demonstra os olhares que alunos-professores têm sobre si e sobre a instituição escolar, do ponto de vista da violência e da criminalização desses acontecimentos. A terceira, vislumbra esboçar o papel que cada ator envolvido exerce no cotidiano escolar.

\section{DimenSões dA VIOLÊNCIA E O CONCEITO DE MEDIAÇÃo: UM MERO INSTRUMENTO NORMATIVO DE RESOLUÇÃo DE CONFLITOS?}

A formalização de processos de mediação está diretamente associada às manifestações de violência presentes em nossa realidade social, as quais assumem diversas modalidades e modos. Em aberto está a busca por respostas às perguntas que ainda continuam em formatações: por que o ideário contido no processo de civilização não foi capaz de evitar atos de barbárie? As sociedades tecnológicas e informacionais terão condições de minimizar esse quadro de expressões? Como pensar, do ponto de vista humano, a formação do indivíduo? Como propor entendimentos mínimos sobre as diversas "violências" experimentadas na realidade brasileira, em especial nos espaços escolares?

$\mathrm{O}$ tema da mediação no interior da escola está relacionado à violência urbana, reverberadas em manifestações de violência na escola. Sabe-se que o conceito de violência abrange dimensões da política, da religião, de caráter institucional e econômica. O conceito do que venha a ser violência continua sendo um complicador àqueles que se habilitam a 
estudá-la (PIMENTA, 2008). Isso se dá pelo seu caráter polifônico e plural, não se podendo excluir as dinâmicas dos diferentes tempos, espaços, culturas, o que nos remete à ideia de existir várias maneiras de compreendê-la.

Em seu sentido etimológico, tomando como base Yves Michaud (1989, p. 8), o núcleo da palavra violência é vis (força, vigor, potência, quantidade, abundância), advinda do verbo latim violentia, e "significa violência, caráter violento ou bravio". Para esse autor, é a força que constitui o que venha a ser violência, tanto no estágio de desrespeito à ordem, em oposição à paz, quanto no caráter brutal da ação, em face do desrespeito à regra por ter passado da medida.

Essa ênfase na equação "violência igual à força" tem relevância para se questionar os propósitos civilizadores das sociedades industriais modernas que fizeram uso de uma "força legítima", por intermédio de suas instituições e forjaram relações harmônicas, mediadas pelas metodologias pedagógicas de formação ao mundo do trabalho e à vida em sociedade.

No campo da sociologia, a violência, considerada como fato social, passou a ter importância e repercussão social quando foge do controle da ordem institucional. Dentro dessa lógica, não é mais negada e recalcada, mas reconhecida como problema que pede soluções. Passa a fazer parte dos fenômenos submetidos à regulação social.

Fora do controle, a violência traz medo, ódio, estigma, preconceitos. Torna-se, no interior das sociedades contemporâneas, um acontecimento banal submetido ao cálculo, à gestão e ao controle. Contudo, a dinâmica da violência traz recursos cada vez mais renovados, de difícil neutralização, redirecionamento e redução.

$\mathrm{O}$ uso da força pela força, sem a devida medida fundamentada em princípios emancipatórios, de respeito às diferenças e à alteridade humana, de constituição de autonomias e solidariedades, em abundância, não deveria ganhar relevância nas sociedades industriais modernas, democráticas. Costa e Pimenta (2006, p. 7-8), salientam que a violência é “[...] praticada pelo Estado, instituições, grupos sociais e religiosos, organizações públicas e privadas, sistemas de comunicação e econômico, pessoas, enfim, por todos nós". Ninguém está imune da possibilidade de praticar e sofrer algum tipo de violência.

No interior da escola um aspecto da violência, traduzida em manifestações conflituosas, é chamado de Bullying. Na ausência de melhor termo à língua portuguesa, bullying, na leitura do trabalho de Fante (2005), é traduzido em agressões físicas, verbais, morais, psicológicas manifestas no ambiente escolar, fenômeno que se traduz em violência e que inviabiliza a paz no seu interior, em que compete aos envolvidos a busca de caminhos para prevenir manifestações conflituosas e agressivas.

Desse universo de manifestações é que se preocupa a mediação e, enquanto processo, se apresenta, inicialmente, com potencial para a resolução dos conflitos. Na concepção de Antônio Carlos Ozório Nunes (2011), os processos de mediação extraídos das práticas jurídicas são formas de restaurar a cultura da paz na escola.

As posições de Ozório Nunes (2011) não diferem das posições jurídicas de Moore (1998) e Lascoux (2006), uma vez que têm o mesmo ponto de partida: o olhar das inovações jurídicas aos conflitos de ordem sociocultural. Os juristas tratam das técnicas trazidas 
pelas práticas forenses, por meio de inovações pela emergência de alternativas às demandas judiciárias. Acreditam que essas técnicas possam ser aplicadas em conflitos sociais no interior das unidades escolares.

A técnica, apreendida e ensinada, vislumbra minimizar as relações competitivas, concorrenciais, de disputa ou de rivalidades e se caracteriza em possibilidade de reestabelecer o bom convívio, o consenso, a partir da concepção de apaziguamento, finalidade da Justiça Restaurativa.

Para Chrispino e Chrispino (2002, p. 83-84), a mediação de conflito na gestão escolar pode assumir as seguintes abrangências: Política Pública. Introdução da Mediação de Conflito e redução da violência no espaço escolar; Justificativa. A escola tem sofrido com inúmeros episódios de violência em vários níveis e com conflitos envolvendo diversos atores. Isto tem causado dificuldade para o alcance de seus reais objetivos; Etapa Principal. Criação das condições para que a escola possua a cultura de mediação do conflito entre todos os seus atores; Etapas Necessárias. Conhecer a cartografia da violência e do conflito no ambiente escolar por meio de uma Avaliação da Violência Escolar; criar a curto prazo um Plano de Segurança nas escolas; estabelecer a necessidade de adequar lentamente os prédios escolares numa visão de escola segura; capacitar pessoal e mudar a dinâmica da gestão; Estratégia. Sensibilizar para a necessidade de se discutir o assunto; conscientizar para a necessidade de mudar a maneira como a escola trata o assunto, e operacionalizar ações efetivas para diminuir os conflitos e reduzir a violência escolar; Abordagem e Parceiros. Iniciar discussão junto aos diretores sobre a maneira de ver e entender o conflito e a violência na escola. Construir o processo com professores, alunos e comunidade; Avaliação Final. Existência de Plano de Segurança da Escola - "PAS nas Escolas" e a instalação de Mediadores de Conflito no ambiente escolar; Ganho Indireto. O aprendizado da mediação do conflito na escola torna-se patrimônio cultural do futuro cidadão. Espera-se que esse tipo de cultura possa ser utilizado em outros setores da relação social.

Esse movimento é jurisdicional e policial-repressivo. É também uma tentativa de estabelecer um sistema de ordem, pela perspectiva da cultura da paz ou do apaziguamento dos conflitos. Fará sentido se a escola conseguir ampliar as suas noções de pertencimento, reconhecimento e comunidade. Trata-se da emergência de se apostar em relações inovadoras entre política educacional-escola-professor-aluno que prescrevam a compreensão da contemporaneidade e estabeleçam concepções de respeito a todos que convivem nas unidades escolares.

A leitura das observações de campo explicita que a escola é um espaço-lugar com potencial para a resolução de seus conflitos. A escola, embora não tendo tempo burocrático para, pedagogicamente, apaziguar suas tensões, tem potencial em disparar os elementos da mediação, uma vez que disponibiliza em suas normativas (projeto político pedagógico) e práticas (ação pedagógica), a noção de pertencimento, de reconhecimento, de comunidade, de juventude, de ator social e de protagonismo.

O pertencimento, da sugestão de Hall $(1997$, p. 8) configura-se por meio das identidades e identificações culturais, uma vez que entende que elas surgem "de nosso pertenci- 
mento a culturas étnicas, raciais, linguísticas, religiosas e, acima de tudo, nacionais". Da promoção do encontro das particularidades da cultura, formal e informal, é que o sujeito experimenta um conjunto de significados. Do compartilhamento dessas experimentações socioculturais é que o sujeito exprime suas afetações pessoais e coletivas, o que constitui um campo efetivo de percepções de mundo e de pertencimento.

Pertencer requer reconhecimento. O reconhecimento mais importante está no plano sociocultural atrelado aos valores, sentidos, significados e significantes que atribuímos à pessoa. O não reconhecimento resulta em exclusão, desigualdades e não acesso aos bens, produtos e serviços disponíveis à sociedade.

Na realidade, o conceito de reconhecimento utilizado foi extraído da elaboração de Paul Ricoeur (2006), traz elementos da esfera jurídica, inerente às sociedades e relações sociais que se pautam na cidadania e na democracia, uma vez que os sujeitos de direito se reconhecem reciprocamente como pessoas capazes de decidir com autonomia individual sobre normas morais, pela obediência à lei. Por conseguinte, o reconhecimento fomenta o respeito cultural, social, político, religioso, singular, simbólico, subjetivo, ético, estético e moral.

A escola-comunidade, conjunto de pessoas agrupadas em determinado espaço institucionalizado ou não, consciente ou não de pertencimento, em constante processo de interação política, cujas relações socioculturais, plurais, dimensionam o sentido da vida interna-externa de seus membros, promovendo modos de ver, sentir e pensar o mundo (SILVA et al., 2003, p. 15-16), se fortalece enquanto lugar de reconhecimento e ganha relevância junto aos processos de formação. A comunidade (BAUMAN, 2001) se constitui nas esferas do político e se traduz em espaço estratégico que organiza as ações e as atitudes das pessoas dentro dos agrupamentos.

Por essa trajetória, a escola se coloca em posição de decifrar os caminhos dos conflitos, das agressões e das manifestações de violência. Esse caldeirão de questões - violência, bullying, pertencimento, reconhecimento, comunidade - precisa ser codificado para além das dimensões repressivas e criminais. Não dá para apostar num esforço de militarização das práticas pedagógicas ou "obediência militarizada", como salientam Guernelli; Machado (2009, p. 84).

A posição de Alain Touraine (1998), quando questiona temas como a "igualdade" e a "diversidade", coloca no centro desse processo o que chamou de "sujeito democrático". Para esse autor, o que se aplica nos processos de mediação é que o sujeito - aquele que tem consciência da realidade em que faz parte e, politicamente, assume a posição de gerir, controlar, participar de transformações, pela ação ou pela produção de si - deve ser colocado na frente da tomada de decisões de sua vida.

Em outros termos, o protagonismo de todos implica permissão ao outro para atuar, A participação deve ser carregada de simetria, para que as decisões políticas sejam participativas. Da mediação jurídica à automediação escolar, a educação tem potencial para assumir o papel de conduzir seus processos internos e, diante da realidade social de nosso tempo, enquanto espaço-lugar de formação, apresenta as habilidades para desencadear ações sólidas de automediação e de resolução de seus conflitos. 


\section{O COTIDIANO ESCOLAR DAS PERSPECTIVAS DO PROFESSOR-ALUNO-ESCOLA: COMO NOS VEMOS?}

A aposta que a escola tem capacidade de promover a automediação implica o reconhecimento da responsabilidade por inúmeros conflitos que acontecem em seu interior. $\mathrm{O}$ enfrentamento político impõe as seguintes questões: como a escola entende agressões e violências? A escola se vê de que forma? De que modo o coletivo vê a escola? Cabe relatar e explorar alguns recortes que contribuem para a constituição de espaços de mediação com potencial de ser ampliado para outras realidades. ${ }^{2}$

As respostas não são fáceis nem imediatas. No cotidiano da escola, observou-se que os conflitos identificados e classificados como sendo graves foram direcionados à intervenção policial, mas a escola tem todas as condições de equacioná-los. Apresentam-se quatro casos que demonstram aspectos das tensões conflituosas vivenciadas no interior da escola característico à prática de mediação, os quais devem ser encaminhados para um processo de resolução. São eles:

\section{Caso 01}

$\mathrm{Na}$ oficina de "letramento de matemática", os alunos estavam fazendo bagunça (jogavam bolinhas de papel e gritavam, de forma geral, entre eles). A professora não impedia nem controlava as manifestações. Todos estavam falando ao mesmo tempo, juntos e aos gritos. O aluno "V" teve um incômodo com o aluno "R" e desferiu contra ele um soco. O aluno "R" esbravejou, aparentando raiva, mas não devolveu a agressão que sofreu. A solução da professora foi a de levar os alunos à diretoria, o que aconteceu com muita resistência dos envolvidos.

Dias depois, houve o encontro com o aluno "R", o qual falou sobre a agressão sofrida. Contou que ficou tirando cópias na sala da diretora como punição, mas que o aluno "V" passou a encará-lo, estufando o peito, falou que "não arrumaria briga porque não queria conversar novamente com a diretora". O conflito não foi equacionado com a conversa realizada com a gestora da unidade escolar, por conseguinte, a tensão não foi resolvida.

\section{Caso 02}

Em uma observação de sala de aula, constatou-se que os alunos mostravam bom comportamento na presença da professora. A professora teve que sair por alguns instantes para resolver problemas administrativos e os alunos começaram a conversar, levantar de seus lugares e brincar de tapas. Ao retornar, demorou algum tempo para que todos se acomodassem e a figura da professora se faz importante como representação da autoridade ou de autoridade pedagógica na condução dos processos formativos naquele espaço.

2 Por questões éticas não será citado o nome de qualquer pessoa contatada durante as observações e entrevistas. No máximo, quando necessário, se utilizará a inicial, fictícia, do primeiro nome. Cabe ressaltar, também, que todas as informações privilegiadas neste artigo foram coletadas na pesquisa realizada, conforme metodologia apontada. 


\section{Caso 03}

A escola se estabelece dentro de verdades ou de posicionamentos que a tornam insensível em diversos planos. Em determinada visita, soube-se que uma aluna pegou piolho e sua tia raspou a cabeça da mesma. No dia seguinte, a mãe mandou a aluna "S" para a escola de boné. A escola, na pessoa de seus funcionários e da professora, cumpriu a regra de que nenhum aluno poderia entrar ou andar de boné em seu interior. Pela insensibilidade da escola, a aluna "S" foi "zoada", como ela argumenta, por todos os colegas de sala.

\section{CAso 04}

No refeitório, para pensar sobre os passos do projeto, duas alunas, "S" e "S", puxaram conversa perguntando: "você é do Conselho Tutelar?" Ao responder de forma negativa, explicando o que estava fazendo na escola, elas começaram a relatar vários episódios de agressão física e verbal que presenciaram. Desde professora chamando alunos de "macaco", proibição do uso de maquiagem às alunas, até agressões verbais e físicas entre alunos.

Esses casos demonstram a urgência de intervenções horizontalizadas entre sistema educacional-escola-gestores-professores-alunos. Contudo, pede-se cautela ao questionar a posição da escola no tratamento dessas manifestações, mas a cautela não impede as transformações de respeito e responsabilidades a todos, uma vez que as agressões não são regras nem devem ser tratadas com generalizações.

Há exemplos positivos de intervenções - Lei Federal Anti Bullying $n^{o}$. 13.185/2015, e Projeto Educação para a Paz e Não Violência, entre outros. No entanto, denota-se que a escola tem dificuldade de transpassar suas regras e permitir que outros atores contribuam na gestão escolar. Equivale dizer, a título de exemplo explicativo, que integralizar as premissas existentes no Programa Mais Educação, conforme a Portaria Interministerial $n^{\circ}$. 17/2007, não é tarefa tranquila, uma vez que ela tem que se esforçar para:

\footnotetext{
IV - prevenir e combater o trabalho infantil, a exploração sexual e outras formas de violência contra crianças, adolescentes e jovens, mediante sua maior integração comunitária, ampliando sua participação na vida escolar e social e a promoção do acesso aos serviços sócio-assistenciais do Sistema Único de Assistência Social - SUAS.
}

$\mathrm{Na}$ visão dos professores, profissionais habilitados para alavancar processos de formação e educativos, a instituição pode ter compreendido essas prerrogativas no campo normativo, mas na prática tem limites e dificuldades humanas, políticas, sociais, culturais, e simbólicas que estão postas pela idealização da autoridade e da ação pedagógicas, nos termos da violência simbólica sugerida por Bourdieu (1983), na imposição de arbitrários culturais, cujos papéis são atribuídos ao professor e às técnicas de ensino-aprendizagem.

A autoridade pautou-se - e ainda se pauta - em plataformas autoritárias entre senhor e servo, na disciplina e no conhecimento centrado na figura do mestre. A relação ensino-aprendizagem se circunscreve pela seleção de conhecimentos que não dão sentido à reali- 
dade do aluno. Nesse descompasso, explicitando as falas extraídas da pesquisa de campo, o descontentamento dos professores caminha na seguinte perspectiva:

Diante de tanta dificuldade, o aprendizado em sala de aula se torna pequeno (...). Acho que os pais deveriam explicar ao filho a importância dos estudos, o valor da educação (...);

(...) Com dificuldade de aprendizagem, mas carentes de afeto; A maioria são imaturos, gritam na sala (...), xingam e não se concentram. Outros precisavam de ajuda profissional como psicopedagoga pois tem problemas de aprendizagem;

São alunos de diversas faixas etárias e diferentes realidades o que dificulta a aprendizagem e o ensinamento (...);

Não têm vocabulário compatível com a série (...);

Não estão acostumados a trazer o material escolar e não têm hábitos de estudos (...). Acredito que muitos estão precisando de acompanhamento médico e principalmente do afeto familiar.

A escola, na visão dos alunos, não favorece o protagonismo, a sensação de pertencimento e de reconhecimento. Para estes, a educação e a escola promovem o sentimento de que foram abandonados a sorte, o que reverbera nas possibilidades de participação de qualidade junto ao modelo de sociedade vigente A obrigatoriedade da educação ou de estudar não significa a segurança de acessar os benefícios do consumo e do mercado disponíveis em nosso tempo social. Entre os diálogos informais efetivados, determinado gestor educacional disse: "temos dois mil alunos. Desses, se dois se salvarem, já fizemos a nossa parte". Ao privilegiar a competição e o mérito, no extremo desse argumento, a escola abandona os alunos que não se adequaram a essa realidade e, pela sensibilidade dos envolvimentos, estes reconhecem a ênfase dessa opção e não vêm sentido da escola para as suas vidas.

$\mathrm{Na}$ dimensão simbólica da violência, o aluno foi colocado à margem da preocupação educacional. À margem, se transformou em problema. Na prática, deixa de ser sujeito principal da existência da escola: ensino-aprendizagem (ALVES; PIMENTA; SOUZA; SILVA, 2010, p. 137-158). Consciente ou não, observou-se a existência de um descaso no tratamento dado aos alunos que segue uma escala hierárquica: do Estado, das Delegacias de Ensino, da Direção da Unidade, da família. Aos alunos, resta a concepção de terem sido transformados em problema ou em culpados de tudo que acontece no entorno e/ou dentro da escola.

A ideia de "má qualidade do ensino" é atribuída ora à incompetência dos professores, ora aos alunos face ao desinteresse ou "pela" violência "na" escola. Os alunos são considerados indisciplinados e, em muitas ocasiões, bandidos, constituindo um conjunto de linguagens conferidas à escola - arquitetura, grades, técnicas de abordagens, livro queixa, disciplina, entre outros - reportam aos sistemas de repressão existentes - prisional e poli- 
cial (SILVA; GONZAGA; MALDONADO, 2015, p. 35-46). Em linhas gerais, as soluções apontadas sobre violência na escola, por professores, diretores e gestores educacionais, estão relacionadas com o aumento no rigor disciplinar e das punições, assim como, aos processos de criminalização dos alunos e de seus atos.

Quando o "alvo" da violência são os alunos, tem-se no seu imaginário a sensação de que o professor o abandonou. Para Barbosa (2016), no âmbito das políticas públicas educacionais, os alunos se transformaram em estatística. Tal aspecto aparece timidamente na fala de alguns professores e demais membros que compõem a estrutura escolar. O aluno não é mais uma criança, um jovem ou um adolescente: é o problema, é o culpado.

Em posicionamentos de pouca formatação democrática, o adulto se impõe, às vezes pela força, sobre o aluno. Denota-se a animosidade nas relações promovidas em seu interior, as quais reproduzem, em certa medida, preconceitos, racismos, machismos, lutas de classe. A escola tem dificuldades em lidar com as diversidades socioculturais, socioeconômicas e sociopolíticas. Denota-se também que a cultura formal, selecionada pela educação, valoriza o silêncio, o não confronto e a obediência, herança autoritária fortemente enraizada em nossa realidade.

\section{EddCAÇÃO, CRIMINALIZAÇÕES E VIOLÊNCIA: OUTRAS POSSIBILIDAdES DE EXPERIÊNCIAS NO COTIDIANO ESCOLAR}

Sabe-se que as "violências" registradas pela unidade escolar são recorridas às resoluções da polícia, do judiciário e da repressão. A escola, por meio do processo de mediação, tem um conjunto de fundamentos e princípios elencados no próprio mister do educar em que se apresentam as eminências pedagógicas de referência aos educadores.

Esses fundamentos e princípios trazem, por si, as concepções que justificam a mediação e estão consignados no projeto pedagógico das unidades escolares estudadas. A escola elabora no Projeto Político Pedagógico (PPP) as diretrizes para as suas ações e norteamentos e, o documento, obrigatório para todas as unidades escolares no Estado de Minas Gerais, tem inspiração em modelos ou exemplos de projetos escritos em outras realidades.

Dentro do PPP formulado pela unidade escolar encontram-se as condições políticas institucionais à promoção de debates, reflexões, diálogos e reelaborações com a capacidade de propiciar ao coletivo os espaços de trocas ativas e participação de atos administrativo-colaborativos de gestão democrática.

O PPP, dentro de suas finalidades educacionais, traz as alternativas para ações e enfrentamentos das dificuldades geradas no cotidiano escolar, mas traz também espaços para automediação. Entre o prescrito e o praticado aparecem as lacunas para a efetivação de gestões participativas, uma vez que nesse entremeio existem determinantes político-ideológico-culturais - despolitização das práticas pedagógicas; educação como espaço moral; seleção da cultura a ser traduzida como formal e adequada; saberes e fazeres hierarquizados verticalmente; usos sociais da formação e da educação - que dificultam relações mais abertas e tracejam os conceitos em retóricas atualizadas ou mero jogo de palavras - escola 
como espaço de formação democrática; formação para a cidadania; autonomia, singularização e emancipação do aluno pelo conhecimento; valorização da criatividade e permissão de protagonismos.

Todos esses princípios estão escritos no PPP da escola estudada, de alguma forma nos seguintes itens: "Finalidades da Escola", "Estrutura Organizacional", "Currículo", "Tempos e Espaços Escolares", "Processos de Decisão", "Relações de Trabalho", "Avaliação". Inclusive, estão presentes nos espaços de atividades extraclasse estabelecidas no horário de trabalho pedagógico (HTP), nos projetos transversais, entre outros.

A educação e a escola são espaços repletos de conflitos, de todas as ordens, advindos intra e extramuros, compostos por inúmeras tensões produzidas por alunos, instituição e profissionais da educação. Tudo em nome de determinada ordem societária ou de uma moral cívica, funcional (ALVES; PIMENTA, SOUZA; SILVA, 2010).

$\mathrm{Na}$ unidade escolar estudada percebeu-se, o que não pode ser considerado como regra ou exceção, um descontentamento entre o papel de ser professor e de ser aluno. A todo instante vê-se o questionamento desses papéis, no sentido de romper com a disciplina proposta pela sociedade moderna, a qual é atribuída à escola e aos professores. As concepções de educação, escola, professor e aluno ganharam outros contornos, que colocam em xeque o conceito de "autoridade" idealizado nesta relação. Vê-se que na experiência escolar ocorreram mudanças do lugar da autoridade, necessários para se aprimorar ações horizontalizadas que rompam com o conceito de hierarquia vertical adotado nas propostas pedagógicas observadas.

As manifestações de violência presentes no cenário urbano, resultantes do sangue, da faca, do revólver, do patrimônio, do medo (COSTA; PIMENTA, 2006; PIMENTA, 2007), adentraram os muros da escola. Em respostas hierárquicas e verticalizadas, vem a crença no uso da força disciplinar, em que o papel e a responsabilidade pedagógica de formação do educador e da educação se deslocam para outros atores: o poder judiciário e a polícia.

A 23 . Promotoria de Justiça de Defesa dos Direitos das Crianças e dos Adolescentes de Belo Horizonte (Infracional) e a Coordenadoria Estadual de Defesa da Educação (PROEDUC) do Ministério Público do Estado de Minas Gerais ${ }^{3}$ lançou uma cartilha promovendo sugestões para um campo de ações interventivas para coibir as manifestações de violências e agressividades na escola.

Essa iniciativa, por mais interessada que esteja na cultura da paz, estabelece, em concomitância, a condução do ato de disciplinar e se habilita em efetivar uma espécie de processo de criminalização das manifestações conflituosas no interior da unidade escolar. Certo que os casos criminais típicos devem ser avaliados pelo sistema judiciário, mas a escola tem a competência em promover as mediações, por ela mesma, tendo em vista que dentro da dinâmica das práticas organizativas da unidade escolar não se caracterizam, no seu tempo burocrático, as condições necessárias (espaços físico, simbólico, coletivo, político, cultural e de sociabilidades) para se evitar, e rever, o processo de criminalização do aluno.

3 Nesse sentido, ver a Cartilha "Educação: semente para um mundo melhor". Documento reeditado em 2016. Disponível em: file:///C:/Users/NEID/Downloads/Cartilha\%20Semente\%20Setembro-2016\%20extranet\%20(1).pdf. Acesso em 7 de maio de 2018. 
A escola não é nem deve ser lugar de polícia, enquanto técnica de aprendizagem por meio da repressão e os processos pedagógicos e educativos formais não podem assumir um caráter criminal. Polícia, Ministério Público e Poder Judiciário acreditam exercer parcerias de combate e repressão às manifestações de violência (BATISTA, 2013), mas colocam em xeque os caminhos da educação universal pautada na alteridade e no direito às diversidades.

A violência, a polícia, o judiciário, a formação, a educação formal, as relações entre pessoas, os protagonismos, as sociabilidades, as diferenças, as singularidades, as desigualdades, as emancipações, as autonomias, as urgências estão "presentificadas" (MAFFESOLI, 2005) na unidade escolar. Essa realidade coloca em evidência as seguintes questões: de que forma a unidade escolar soluciona as demandas institucionais que lhe compete? Quais as práticas de encaminhamento daqueles que extrapolam as suas competências? Qual é o seu papel dentro da realidade escolar contemporânea?

A realidade impõe à unidade escolar a responsabilidade - no sentido institucional pedagógico - de enfrentar suas questões e não deslocá-las para outras instituições estranhas às competências da educação formal. Impõe também um repensar sobre as matrizes convencionais utilizadas no processo pedagógico para que possam visualizar as manifestações que lhe escapam. Essas perspectivas, a do enfrentamento e a da visualização de suas demandas internas, fortalecem a necessidade da leitura das novas exigências, de comprometimentos e responsabilizações com outras manifestações socioculturais "na" e "no entorno" da escola.

As técnicas e os processos de automediação, no sentido das possibilidades de resolução dos conflitos, ganham relevância diante da realidade exposta. Trata-se de uma aposta, um caminho para responsabilizar alunos, professores, gestão escolar e instituição. Esse exercício de responsabilização pode permitir a configuração de novo quadro de relações no interior das escolas, para que se busquem alterações de valores entre alunos-professores-escola. E se minimize o acirramento dos conflitos, na promoção da conquista da confiança institucional, por conseguinte, a confiança de professores e de alunos para com o papel da escola.

A violência é um problema da agenda pública e ganha acento na realidade escolar. O Estado, a sociedade e os profissionais da educação têm a capacidade de tomar providências que modifiquem essa realidade. A educação e a escola devem buscar o entendimento das dimensões socioculturais da violência na contemporaneidade - as relações sociais são conflitivas -, mas se faz necessário estar preparado para o enfrentamento da sociedade do conflito. Conflito, aqui subentendido, como um processo de dialógos, conversações, ideias contraditórias, diferenças, cada vez mais latentes no mundo contemporâneo, que só podem ser compreendidas se alargarmos a nossa capacidade de tolerância e de respeito ao outro, permitindo às pessoas exercerem suas liberdades para questionamentos da ordem. Portanto, o conflito está pautado na tolerância, no fortalecimento dos direitos civis, sociais, culturais, econômicos, simbólicos, dentro de um campo político em que as relações de força e de poder reconheçam no outro, qualquer que seja o outro, sua capacidade de ser proprietário do seu próprio destino. ${ }^{4}$

4 A ideia de "sociedade do conflito" foi discutida por Pimenta (2008, p. 7-24), no texto Dimensões Socioculturais da Violência: contemporaneidade e relações sociais. 
Esse conflito, estruturado em fundamentos das noções de pertencimento, de reconhecimento, de comunidade, de juventude, de ator social e de protagonismo, fomenta identidades, afirmações, autonomias, emancipações, superações das desigualdades e das singularidades. Dentro dessa perspectiva, o conflito se faz necessário. Presente como um movimento dialético, este deve se pautar pela tolerância, capacidade de escuta ao outro e respeito às diversidades, o que se faz emergente no amadurecimento das relações sociais.

A escola poderia apostar nas técnicas de mediação para colaborar no aprimoramento da capacidade de se respeitar as alteridades, mesmo que debaixo de técnicas interventivas, visto que valoriza e transcreve em suas propostas pedagógicas os fundamentos e os princípios que embasam a dialógica dos conflitos.

A mediação propõe pequenas ações para prevenir agressões e violências. Por meio dela se reconhece que não se trata de tarefa tranquila, pelos seguintes motivos: a realidade brasileira mostra o quanto de autoritarismo e de hierarquização vertical que compõem a construção e o imaginário social de nossas relações sociais; o conflito promove a dialética da transformação, uma vez que a diversidade se apresenta como um desafio para a emancipação e o fortalecimento das tolerâncias; a mediação pressupõe movimento coletivo, com respeito e valorização dos direitos em plano horizontal, nunca verticalizado, ou de cima para baixo, e individualizado.

De posse dessas dificuldades, escola e educação formal devem constituir seus espaços de trocas efetivas entre professores, alunos, comunidade, entorno e unidade escolar, sem perder de referência os princípios que reconheçam no outro as suas dimensões políticas. Em igual proporção, portador de direitos e, nessa condição, valorize e respeite um conjunto mínimo de direitos necessários à dignidade humana.

A aposta nos processos de mediação emerge das seguintes questões: como proceder nas intervenções restaurativas do bom convívio e da paz social? Quando o professor e a escola, entendendo a mediação como uma aposta pedagógica educacional, pode propor a mediação dos conflitos? Na unidade escolar, os fatores que podem gerar confrontos circunscrevem-se ao fato de se buscar o entendimento de seu tempo social a partir de estratégias competitivas, concorrenciais, disputas estéticas e performáticas, as quais desestabilizam os sentimentos de pertencimento, de reconhecimento e de comunidade.

O professor-aluno-escola tem que lidar a atual forma de difusão das informações, as quais valorizam enunciados morais, éticos e estéticos dissimuladores da realidade que disparam vontades e desejos de consumo, bem como despertam constantes resultados de interpretações e significados líquidos, líquidos da perspectiva de Bauman (2001), alienantes e contraditórios.

Acredita-se que é na vida em comunidade, no caso escolar, que o indivíduo pode se encontrar, apoiar, interagir, ter proteção e se constituir como pessoa com os seus pares. A comunidade traz proteção e acolhimento, mas a unidade escolar, embora tenha projeto de escola aberto, associação de pais e mestres, grêmios estudantis, entre outros, se recusa a enfrentar as situações de confrontos ou nega a existência deles em seus domínios.

As ações e intervenções pedagógicas ainda são pautadas pela orientação autoritária resistente na sociedade brasileira e suas práticas disciplinares não compreendem os acon- 
tecimentos conflitivos, mesmo porque sua autoridade pedagógica faz prevalecer a posição hierarquizadora da educação e da escola.

As falas recorrentes no interior da unidade escolar são a de que o professor e a escola perderam a autoridade: “(...) Falta de disciplina, limites, respeito com os colegas e funcionários (...)”; “(...) Saudade dos militares!”

A polícia vai à escola. Não é seu papel intervir nos processos pedagógicos educacionais, o que não significa afastá-la das necessárias intervenções. No campo pedagógico, não se pode delegar suas competências para outros setores institucionais.

A unidade escolar tem condições pedagógicas para observar os confrontos ou as tensões, por meio de seus recursos didáticos, e se caracterizar como espaço-lugar de convívio em comunidade, por conseguinte de mediação, bem como, de predisposição para intervenções efetivas de processos restritivos e construtivos de resolução de conflitos.

Restritiva para estabelecer a normalidade relacional no cotidiano das práticas escolares na unidade, no sentido de enfraquecimento e rompimento das relações agressivas, existentes ou preexistentes. Construtiva, face à prospecção de fortalecimento das relações sociais, com base em princípios da cooperação, colaboração e solidariedade entre pessoas, grupos e instituição, com visível faceta de valorização da pessoa humana.

Para esses caminhos, a unidade escolar privilegia a voluntariedade, a autonomia das decisões, a dissimulação das controvérsias, o consenso, a confidencialidade na dimensão pedagógica da educação, a informalidade da intervenção, a linguagem próxima da realidade dos envolvidos, o diálogo - essa é a tônica do PPP estudado.

Esses privilégios dão à mediação a dimensão de razoabilidade e de amplitude. $\mathrm{O}$ mediador é, acima de tudo, um educador. Na qualidade de educador, deve viabilizar a comunicação entre os mediados, no sentido de que organiza, em conjunto com os envolvidos, a compreensão deles sobre o que os levaram às agressividades e ao conflito. A proposta de mediação pela unidade escolar se constitui dentro de princípios que fortalecem as formas de cooperação e, fora delas, aumentam as dificuldades do estabelecimento do consenso.

Faz-se necessário admitir a importância da constituição de espaços escolares, reconhecidamente legítimos e legitimados pelo coletivo da unidade escolar - alunos, professores, gestores e comunidade-entorno -, no sentido de que, juntos, realizem processos de participação e resolvam-minimizem os conflitos do cotidiano escolar.

Cooperar passa a ser uma busca pelo entendimento das dinâmicas daquele lugar, em que a postura colaborativa deve contagiar pessoas e grupos aos diferentes modos de resolução dos conflitos. Há riscos. Riscos, face à unidade escolar assumir a responsabilidade de demandas sociais que tecnicamente não lhe cabem. Riscos, porque se estabelece a oportunidade de superar os modelos pedagógicos disciplinares, resistência que o sistema educacional exala.

A educação compõe um conjunto de conhecimentos inerentes à gestão da unidade escolar, quais sejam: conhecimento, traduzido pelo conjunto de saberes de que se circunscrevem a tensão produzida entre as partes, como estratégia capaz de leitura de um conflito; habilidade ou o saber-fazer, no sentido de aquisição de experiência para o domínio das 
questões pertinentes à existência de conflitos; e, atitude, na perspectiva do querer fazer, implicado na vontade, ou não, de fazer coisas convergentes ao reestabelecimento da comunicação entre os envolvidos em atos de agressividade ou manifestações de violência.

No campo da automediação, a escola não tem a clareza de como promover a comunicação entre os conflitantes e se fortalece na tecnicidade (formação para as necessidades do mercado) e na burocracia (voltada para a preparação dos alunos às avaliações periódicas etc.). Trata-se de configuração de relações maduras que promovam direitos e despertem, a partir da alteridade, o respeito às diferenças e às diversidades.

Esperam-se posturas de resgate da dimensão política do processo educacional, pautado na formação da pessoa e no enfrentamento das dimensões humanas da sociedade, não para servir ao mercado, ao mundo do trabalho e ao consumismo. Portanto, caracterizar as diferentes formas de violência para, a posteriori, promover intervenções, requer atitudes de mediação, nas quais não desconhecem as noções de pertencimento, reconhecimento, comunidade, ator social e protagonismo.

\section{CONSIDERAÇões FINAIS}

As manifestações de violência passaram a compor o universo das relações e do cotidiano escolar. O que era uma preocupação dos grandes centros urbanos ganhou recorrência nas dinâmicas das escolas das cidades de médio e pequeno porte.

O controle desses eventos localizados no ambiente escolar passou a ser uma das dificuldades da educação e da escola contemporânea, no sentido de trazer soluções aos diversos embates enfrentados por professores, alunos, gestores e funcionários, em face dos seus efeitos sociais, resultados da superioridade de uns sobre os outros, da violência moral, do sangue, da morte, da agressão, do revólver, da faca.

Os gestores, professores e alunos não sentem que a unidade escolar tem a devida competência para resolver as diferentes manifestações de violência e agressividades em ocorrência sobre sua circunscrição. Essa ausência de percepção traz consigo uma crescente interferência de outras instituições na educação. As interferências são bem-vindas, desde que não sobreponham ou coloquem em xeque a competência da educação e, desde que ainda, fortaleçam atividades-ações interdisciplinares e transversais reforçadas pela idealização da cidadania, participação, comunidade, transparência, emancipação, diversidades, singularidades e cooperações.

No entanto, o que se observa, a partir dos dados empíricos da pesquisa, é a presença crescente de parcerias entre as unidades escolares com o Ministério Público, as Polícias e o Poder Judiciário. As intervenções dessas instituições podem ser frutíferas como apoio de propostas que intensificam atitudes disciplinares e repressivas, mas coloca em xeque a validade das práticas e técnicas pedagógicas dentro do projeto civilizador que a educação formal se propõe realizar.

Dessa relação emergem diferentes procedimentos de intervenção que propugnam resoluções de conflitos, mas enfatizam práticas de criminalização dos envolvidos, tanto pela 
via administrativa quanto pela via militar-judicial, embora se difunda uma suposta cultura da paz, o que intensifica as desconfianças e as dúvidas sobre a ação pedagógica e o papel da educação formal de cunho disciplinar.

Explicitá-la requer evidenciar os elementos de mediação praticados no cotidiano escolar, conscientes ou não, os quais traçam ressignificações às manifestações de agressividades e as ações pedagógicas. Dentro desse pressuposto se apresenta a mediação, técnica a ser praticada pelos próprios atores envolvidos no contexto escolar, face ao favorecimento da superação do indivíduo vitimizado e do combate de atitudes discriminatórias.

Entender a força da educação, do educador e da escola sobre a formação do aluno requer a exploração das possibilidades normativas e pedagógicas existentes que podem contribuir para a superação de uma provável intensificação de posturas de criminalização-policial-repressiva no interior da escola.

É dentro das bases de concepção do conceito de educação universal e pública que se estabelecem as diretrizes políticas pedagógicas à busca por superar as desigualdades educacionais, por estabelecer práticas cidadãs efetivas e para erradicar todas as formas de discriminação. Esse quadro de perspectivas se configura dentro de uma lógica de gestão democrática da educação assumindo o seu caráter universal, de respeito aos direitos humanos, à diversidade e à sustentabilidade socioambiental.

Na prática, a unidade escolar elabora o seu PPP e define seus traçados político (espaço de formação de cidadãos conscientes), pedagógico (processos abertos de ensino-aprendizagem abertos e participativos, currículo que contemple as diversidades, a realidade do entorno), social (sociabilidades socioculturais, comunitárias, associativas, lazer, condições de trabalho etc.) e gestão (conselhos, grêmios, estilo de gestão transparente, planejamento orçamentário coletivo, relações escola e comunidade, parcerias com a sociedade civil). Dentro desse quadro de princípios é que se pauta a obrigação institucional de retomada de sua competência frente aos processos de formação dos alunos.

O PPP traz a possibilidade de superar a postura de criminalização-policial-repressiva aplicada às manifestações conflitivas no interior da escola. Não se pode dizer que a escola e os professores estejam inertes. O problema se desloca para distintos campos da ação pedagógica e da didática que carecem de outras práticas e técnicas-tecnologias para o seu enfrentamento, na perspectiva de se evitar modelos educacionais bancários voltados ao mercado. Ter as condições normativas ou os critérios funcionais estabelecidos não contribui para a efetivação do prescrito, visto que a educação se configura num campo de disputas políticas e de jogos de força que não devem, nem podem, ser desprezados.

A pergunta que estabelece a reflexão e o título deste trabalho inscreve pela aposta aos processos de mediação como uma possível "prática-atitude" de resolução de conflitos escolares e coloca em pauta as tendências de criminalização dessas manifestações, mas também problematiza a importância das prerrogativas do ato de educar oferecido pela escola.

Para a ressignificação dessas "escolhas" de criminalização-policial-repressiva, a educação e a escola precisam entender que são também responsáveis para a efetiva participação dos atores na busca da resolução de seus conflitos, enquanto tomada de decisão de seus 
destinos. Da pulverização dos comprometimentos e das responsabilizações institucionais é que advêm caminhos desejáveis à consolidação do "respeito mútuo", um dos fundamentos do processo de mediação.

Pela efetivação desses princípios, a escola tem um papel didático-pedagógico preponderante, inequívoco, mas a realidade vivida em seu cotidiano explicita a existência de um sistema que não atende, em suas premissas básicas, a uma formação pessoal-profissional aberta $\mathrm{e}$ humanizadora. Na prática, contradizem-se os discursos e as retóricas utilizadas em seu PPP, relevantes pela aposta na consolidação da democracia, da cidadania, da cultura da paz e das emancipações, as quais se predispõem a realizar, mas têm dificuldades de efetivação.

$\mathrm{Na}$ efetivação dos processos de mediação, a escola passa a ter a oportunidade de consolidação de espaços de aprendizagem, marcadamente de solidariedade, de convívio coletivo e comunitário, de participação, de protagonismo e, acima de tudo, de valorização e de respeito às pessoas.

Uma resposta afirmativa fica em aberto, merecendo acompanhamentos e aprofundamentos, pois do prescrito e do recurso discursivo à efetividade de outra escola há muitos caminhos a percorrer. Estes devem valorizar o coletivo ou a comunidade escolar, envolver-se em princípios e pertinências com a ética, a moral (entendido como regras de convívio e convenções compartilhadas), o respeito mútuo, as singularidades e as tolerâncias.

Esse percurso deve promover a educação para a vida e o mundo, não para a competição, individualismo e concorrência. Este é um dos desafios da Educação: institucionalizar práticas de mediação e resolução de seus conflitos, para que a escola tenha as condições de evitar o abafamento de outras formas de convívio que não se pautem pelo respeito, alteridade, singularidade e emancipação, permitindo que todos os envolvidos possam se constituir num ator social e se dotar de protagonismo à construção de experiências transformadoras.

\section{Agradecimentos}

À CAPES e à FAPEMIG, pelo apoio.

\section{REFERÊNCIAS}

ALVES, Cecília Pescatore; PIMENTA, Carlos Alberto Máximo; SOUZA, Régis Toledo; SILVA, André Luiz. Educação e Mediação: apontamentos teóricos para o debate sobre políticas públicas. In: PIMENTA; ALVES (Orgs.). Políticas Públicas e Desenvolvimento Regional. Campina Grande, PB: EDUEPB, 2010, v. 1, p. 137-158.

BARBOSA, Josirene de Carvalho Barbosa. Desenvolvimento e Educação: O Projeto Societário Subjacente às Políticas Públicas para o Ensino Médio. Itajubá, MG: Universidade Federal de Itajubá. Dissertação (Mestrando em Desenvolvimento, Tecnologias e Sociedade), 2016.

BATISTA, Luiz Fernando. Análise sobre a Implantação do Núcleo de Mediação de Conflitos na cidade de Poços de Caldas, no ano de 2012, como da violência e das ações 
delituosas entre os conflitantes. Belo Horizonte: Academia de Polícia Militar (Monografia - Curso de Especialização em Segurança Pública), 2013.

BAUMAN, Zygmunt. Modernidade Líquida. Rio de Janeiro: Jorge Zahar Ed., 2001.

BOURDIEU, Pierre. Questões de Sociologia. Rio de Janeiro: Marco Zero, 1983.

BOURDIEU, Pierre et al. Compreender. In: A miséria do mundo, 17. ed. Petrópolis, RJ: Vozes, 1997, p. 693-732.

CHRISPINO, Álvaro e CHRISPINO, Raquel. Políticas educacionais de redução da violência: mediação do conflito escolar. São Paulo: Editora Biruta, 2002.

COSTA, Márcia Regina; PIMENTA, Carlos Alberto Máximo. Violência: Natural ou Sociocultural? São Paulo: Paulus, 2006.

FANTE, Cleo. Fenômeno Bullying. Programa Educar para a Paz. Campinas, SP: Versus Editora, 2005.

GUERNELLI, Sonia Maria Dos Santos; MACHADO, Vera Lúcia De Carvalho. A Escola na ótica de alunos de ensino médio de diferentes tribos. In: Comunicações. Piracicaba, SP, ano 16, n. 1, jan./jun. 2009, p. 75-87.

HALL, Stuart. Identidades Culturais na Pós-Modernidade. Rio de Janeiro: DP\&A Editora, 1997.

LASCOUX, Jean-Louis. O que é a mediação? 2006. Disponível em: http://www.forum-mediacao.net/module2display.asp?id=39\&page=2. Acesso em: 18 de outubro de 2015.

MAFFESOLI, Michel. A Transfiguração do Político: a tribalização do mundo. Jaguaré do Sul, SC: Salinas, 2005.

MICHAUD, Yves. A Violência. São Paulo: Ática, 1989.

MOORE, Christopher W. O processo de mediação: estratégias práticas para a resolução de conflitos. Porto Alegre: Artmed, 1998.

NUNES, Antônio Carlos Ozório. Como Restaurar a Paz nas Escolas, um Guia para Educadores. São Paulo: Ed. Contexto, 2011.

PIMENTA, Carlos Alberto Máximo. Dimensões Socioculturais da Violência: contemporaneidade e relações sociais. In: Sociedade em Debate (UCPel), v. 1, 2008, p. 7-24.

PIMENTA, Carlos Alberto Máximo. Juventude, violência e políticas públicas. Revista Espaço Acadêmico. Ano VII, n. 75, ago. 2007, mensal.

RICOEUR, Paul. Percurso do reconhecimento. São Paulo: Loyola, 2006.

SILVA, Antônio Carlos Barbosa da; GOULART, Benedito Donizeti; PIMENTA, Carlos Alberto Máximo; SANTOS, Maria Teresa dos; RESCHILIAN, Paulo Romano; SOUZA, Régis Toledo. A Extensão Universitária e as Bases Metodológicas da Ação Interdisciplinar. In: Revista de Extensão Universitária. Taubaté, SP: UNITAU, ano 1, n. 1, 2003, p. 11-28. 
SILVA, Clemildo Anacleto da; GONZAGA, Jorge Luiz Ayres; MALDONADO, Luciene. Escola e violência: Semelhanças entre a linguagem utilizada para se referir à violência escolar e a linguagem do meio policial. In: Ciência em Movimento. Porto Alegre, ano XVII, n. $34,2015-1$, p. 35-46.

TOURAINE, Alain. Igualdade e diversidade: o sujeito democrático. São Paulo: EDUSC, 1998.

\section{Dados dos Autores:}

Carlos Alberto Máximo Pimenta

Doutor em Ciências Sociais pela Pontifícia Universidade Católica de São Paulo (PUC/SP); Professor no Programa de Pós-Graduação em Desenvolvimento, Tecnologias e Sociedade (PPG DTecS) da Universidade Federal de Itajubá (UNIFEI) e coordenador do Núcleo de Estudos Interdisciplinares em Desenvolvimento (NEID). Itajubá/MG - Brasil. carlospimenta@unifei.edu.br

\section{Ligia Maria de Mendonça Chaves Incrocci}

Doutoranda em Ciências da Tecnologia pela Universidade Federal de São Carlos (UFSCar); mestre em Desenvolvimento, Tecnologias e Sociedade (PPG DTecS / UNIFEI). Itajubá/MG - Brasil. ligia.incrocci@gmail.com.

Submetido em: 09/05/2017

Aceito em: 14/06/2018 